\title{
Spatial-temporal analysis and visualization of scarlet fever in mainland China from 2004 to 2017
}

\author{
Wei-tong Li, Rui-hua Feng, Tong Li, Yan-bing Du, Nan Zhou, Xiu-qin Hong, Shang-hui Yi, \\ Wen-ting Zha, Yuan Lv
}

\author{
Key Laboratory of Molecular Epidemiology of Hunan Province, School of Medicine, Hunan Normal \\ University, Changsha, Hunan, People's Republic of China
}

\begin{abstract}
This study analysed retrospectively the spatio-temporal distribution and spatial clustering of scarlet fever in mainland China from 2004 to 2017. The incidence of scarlet fever has been increasing in recent years. Previous studies on the spatial distribution of scarlet fever in China have mainly focused at the provincial and municipal levels, and there are few systematic reports on the spatial and temporal distribution characteristics of scarlet fever at the national level. Based on information obtained from the China's Centre for Disease Control (China CDC) on the incidence of scarlet fever, we explored systematically the spatial-temporal distribution of this disease by three methods: spatial autocorrelation analysis, spatial-temporal scanning analysis and trend surface analysis. The results demonstrate that the incidence of scarlet fever varies by season, generating one peak from May to June and a second from November to December, with February and August
\end{abstract}

Correspondence: Wen-ting ZHA, Key Laboratory of Molecular Epidemiology of Hunan Province, School of Medicine, Hunan Normal University, Changsha, Hunan, 410081, People's Republic of China.

Tel.: +86.13574103095.

E-mail: 183259829@qq.com.

Key words: Scarlet fever; Geographic Information System; Spatialtemporal distribution; Trend surface analysis; China.

Conflicts of Interest: The authors declare no potential conflict of interest.

Funding: This research was funded by JG2018B041, Education Project of Hunan Provincial Department (2017 No. 451) and (2017 No. 452).

Acknowledgments: We are grateful to everyone who helped us to complete this study successfully.

Received for publication: 11 November 2019

Accepted for publication: 25 March 2020

(C) Copyright: the Author(s), 2020

Licensee PAGEPress, Italy

Geospatial Health 2020; 15:831

doi:10.4081/gh.2020.831

This article is distributed under the terms of the Creative Commons Attribution Noncommercial License (CC BY-NC 4.0) which permits any noncommercial use, distribution, and reproduction in any medium, provided the original author(s) and source are credited. show a comparatively low number of cases. Trend surface analysis indicates that the incidence of scarlet fever in northern China is higher than in the South, slightly higher in the West compared to the East and lower in the central part. Additionally, the results show that there are regions with clusters of scarlet fever distributed in the Centre, Northeast, Northwest, and North as well as in some eastern provinces, such as Zhejiang, Shanghai, Shandong and Jiangsu.

\section{Introduction}

Scarlet fever, an acute respiratory infectious disease caused by the group A Streptococcus bacterium, is common in children, especially at ages between 5 and 15 (Liu et al., 2014; Ning et al., 2018). The clinical symptoms include sore throat, high fever or skin infection and the characteristic red rash. A small number of patients have also heart, kidney and joint damage due to an allergic reaction. Scarlet fever is mainly transmitted through respiratory droplets or direct contact with mucus, saliva or skin, and some outbreaks can also be transmitted by food (Yang et al., 2007). So far, there is no effective vaccine (You et al., 2011). After the 20th century, the mortality rate of scarlet fever has declined considerably thanks to improvement of health care level, but outbreaks at different scales continue to be reported. Examples include Australia, Hong Kong, Vietnam, U.K. and U.S.A. (Lau et al., 2012; Wong et al., 2012; Andrey et al., 2016; Wong et al., 2018). In China, the incidence per 100,000 people has risen from 1.46 in 2004 to 5.68 in 2018. Scarlet fever epidemic and outbreaks have occurred in many areas of China, even with several death cases in Beijing and Shanghai (Wu et al., 2017; Kong et al., 2017).

Geographic Information System (GIS), a comprehensive, computerized system capable of collecting, saving, managing, calculating, displaying and analysing spatial-temporal data effectively, is widely used to describe the epidemic characteristics of infectious diseases and analyse their spatial distributions (Tang, 2011; Tami et al., 2016; Kirby et al., 2017; Zhang et al., 2019). GIS also provides opportunities for understanding diseases from different perspectives. While current Chinese papers about the spatial and temporal distribution of scarlet fever rarely apply a perspective of the disease dealing with the national level, they rather focus at the provincial and municipal levels. We therefore studied spatial-temporal distribution characteristics of scarlet fever in mainland China at the provincial and national levels. Based on GIS technology and spatial statistics, we explored areas and periods at high risk to provide a reference for targeted, comprehensive prevention and control of scarlet fever in China. 


\section{Materials and Methods}

\section{Study area and data sources}

This study concerns mainland China, which includes 31 administrative regions (23 provinces, 5 autonomous regions, 4 municipalities, and 2 special administrative regions) covering an area of approximately 9.6 million $\mathrm{km}^{2}$, is locates in eastern Asia on the western border of the Pacific Ocean (Figure 1). According to the $6^{\text {th }}$ census data (National Bureau of Statistics of China http://www.stats.gov.cn/), the total population of the mainland is 133.28 billion, including 23.93 billion children aged $0-15$ (18\%). The incidence data of scarlet fever in mainland China from 2004 to 2017 were obtained from China Public Health Science Data Centre and the China Centre for Disease Control (China CDC), (http://www.chinacdc.cn/).

\section{Thematic map of incidence of scarlet fever}

Firstly, we divided the incidence of scarlet fever into 6 levels and used colour shades to indicate changes in morbidity: the darker the colour, the higher the incidence. Afterwards, we used the ArcGIS, v. 10.2.2 software (ESRI, Redlands, CA, USA) to produce the thematic provincial maps of the incidence of scarlet fever from 2004 to 2017.

\section{Spatial autocorrelation analysis}

Spatial autocorrelation analysis (Moran, 1950; Tsai et al., 2009; Jiang et al., 2011) is a common method to analyse the similarity of spatial data and quantitatively analyse the characteristics of spatial distribution in spatial units. Moran's $I$ cannot only be calculated to analyse the spatial correlation of the entire research area (global autocorrelation), but also the spatial clustering in some specific areas (local autocorrelation). This index ranges from -1 to +1 indicating a positive correlation when the value is $>0$ at a statisti- cally significant level; negative correlations are treated in a similar manner when the index is $<0$. Local Moran's $I$ coefficient represents four different spatial clustering modes: High-High $(\mathrm{HH})$ (hotspots), Low-Low (LL) (coldspots), High-Low (HL) and LowHigh (LH). Spatial autocorrelation analysis was performed using the univariate (local) Moran's $I$ tool in the GeoDa software (http://geodacenter.asu.edu). The significance level was set at $p<0.05$ and $95 \%$ confidence level with the number of simulations at 999 .

\section{Spatial-temporal cluster analysis}

In this study, the monthly incidence was taken as the clustering unit and the province as the minimum spatial unit; The maximum scanning radius was set as $30 \%$ of the total population and the maximum scanning time was set as $30 \%$ of the total research time. The Log Likelihood Ratio (LLR) was calculated on the basis of the Poisson distribution model. The $p$-value of LLR was obtained by the Monte Carlo method with the simulation time 999. The analysis process was carried out using the software SatScan9.4 (http://www.satscan.org) and the scanning results were visualized by ArcGIS, v.10.2.2.

\section{Trend Surface Analysis (TSA)}

Trend surface analysis (Xue et al., 2004), which is based on the theory of multiple regression analysis and least square method, fits mathematical surfaces according to sample data and uses trendsurface equation models of different orders to explore the spatial distribution of diseases and find the local variation. According to previous studies (Xue et al., 2004), we selected a 2-order trend surface model to analyse the overall trend of the incidence of scarlet fever and establish a three-dimensional view by ArcGIS, v.10.2.2.

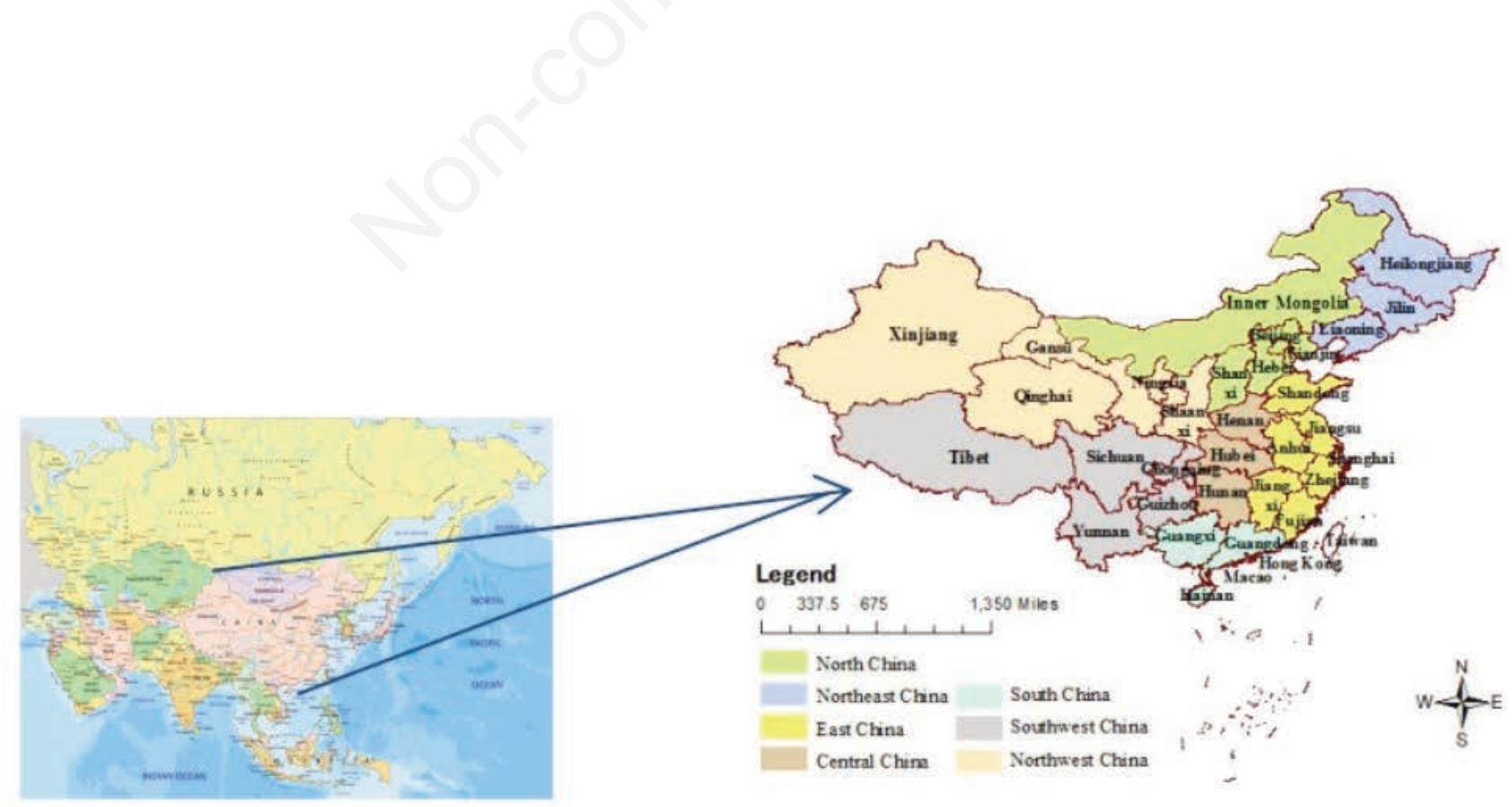

Figure 1. Geographic location of China and its provinces (municipalities, autonomous regions). 


\section{Results}

\section{The temporal distribution of scarlet fever}

From 2004 to 2017, a total of 576,532 cases of scarlet fever were reported nationwide accumulatively, with an average annual incidence of 3.06 per 100,000 people. The incidence of scarlet fever in China increased per 100,000 people from 1.46 in 2004 to 5.39 in 2017 , showing an overall upward trend $\left(\chi^{2}=8.785\right.$, $p<0.01$ ), (Figure 2). The monthly incidence of scarlet fever in China from 2004 to 2017 is shown in Figure 3. The incidence of scarlet fever has an obvious seasonal increase, with a double-peak distribution. The first peak occurring from May to June, and the second from November to December, while February and August have the lowest number of cases each year.

\section{Thematic map of incidence of scarlet fever}

The spatial distribution of scarlet fever in mainland China from 2004 to 2017 is shown in Figure 4. We can see that the disease struck

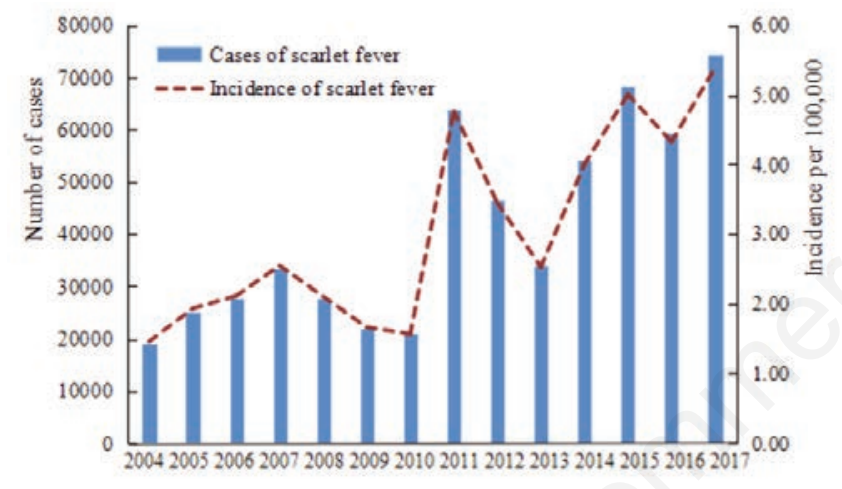

Figure 2. Annual trend of scarlet fever in China 2004-2017.

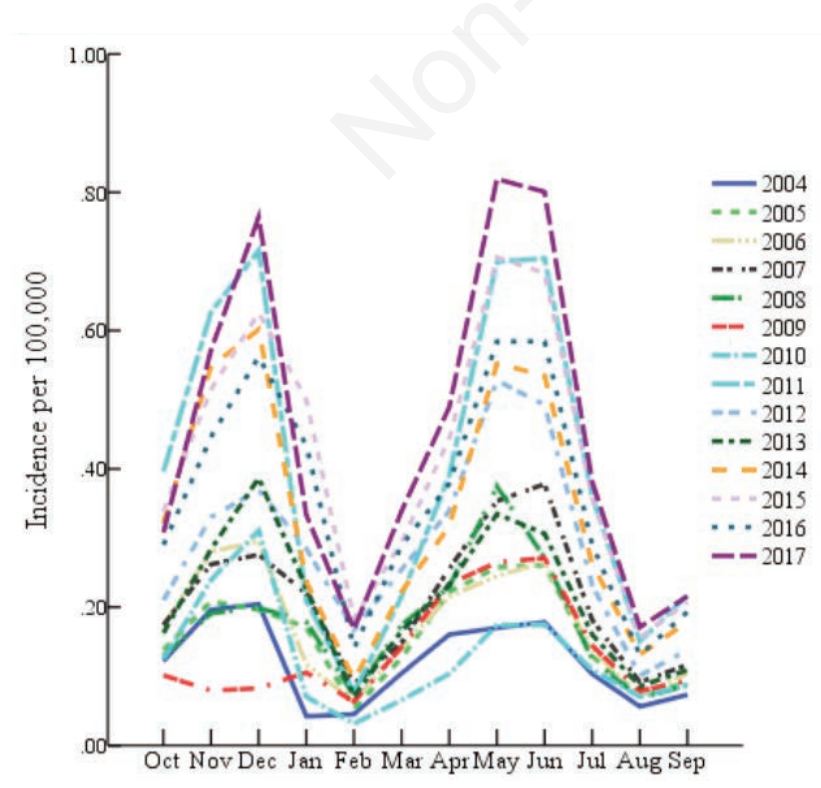

Figure 3. Monthly incidence of scarlet fever in China 2004-2017. in all parts of the country, with a higher number of cases in the northeastern, northern and north-western part of the country, especially in Liaoning, Jilin, Heilongjiang, Beijing, Tianjin, Xinjiang and Inner Mongolia, while Hunan, Hubei, Jiangxi, Anhui, Guangxi, Guangdong, Hainan, Fujian and other southern regions (Shanghai excepted) had a low incidence. Overall, however, the incidence of scarlet fever had a tendency to spread in the southern direction.

\section{Spatial autocorrelation analysis}

The results of global spatial autocorrelation analysis showed that the annual Moran's $I$ of scarlet fever in mainland China ranged from 0.2892 to 0.4975 between 2004 and 2017, with a statistical significance of $p<0.05$ (Table 1). The results indicate that there was an evident spatial positive correlation binding the cases of scarlet fever together, each year showing up as high levels of spatial clustering and dependence. However, the annual change of the Moran index was not statistically significant $\left(\chi^{2}=0.173, p>0.05\right)$, which means that the spatial autocorrelation of scarlet fever did not increase. The local spatial autocorrelation analysis showed that the incidence of scarlet fever in mainland China had an obvious clustering. The $\mathrm{HH}$ and LL cluster regions showed little difference between the different years. The $\mathrm{HH}$ cluster regions, indicating hotspots, were mainly concentrated in Inner Mongolia and areas in the Northeast, while the LL cluster regions, indicating coldspots, were mainly concentrated in more southern and south-eastern provinces. As seen in Table 2 and Figure 5, Shandong was a HL cluster region in 2016.

\section{Spatial-temporal clustering scanning analysis}

The purely spatial scanning results showed that large cluster region existed every year from 2004 to 2017, while there were 610 provinces with clusters, all of which had a high risk of incidence, Relative Risk (RR) ranged from 2.51 to 6.74. From 2004 to 2015, the spatial clustering of scarlet fever was centred in Heilongjiang $(47.8613 \mathrm{~N}, 127.7630 \mathrm{E})$ and mainly distributed in 6 provinces situated in the north-eastern and northern parts of China.

Table 1. Global spatial autocorrelation analysis of scarlet fever incidence in China, 2004-2017.

\begin{tabular}{lccccc} 
Year & Moran's $I$ & Means & SD & Z-value & p-value \\
2004 & 0.3673 & -0.036 & 0.1081 & 3.732 & 0.001 \\
2005 & 0.2892 & -0.0319 & 0.1063 & 3.0203 & 0.006 \\
\hline 2006 & 0.3753 & -0.0381 & 0.1076 & 3.8408 & 0.003 \\
2007 & 0.4673 & -0.0392 & 0.1076 & 4.706 & 0.001 \\
\hline 2008 & 0.4919 & -0.037 & 0.1116 & 4.7396 & 0.001 \\
2009 & 0.4555 & -0.0337 & 0.1173 & 4.1709 & 0.002 \\
\hline 2010 & 0.4975 & -0.038 & 0.1098 & 4.8759 & 0.001 \\
2011 & 0.4063 & -0.0365 & 0.1082 & 4.0917 & 0.001 \\
\hline 2012 & 0.4411 & -0.0352 & 0.1168 & 4.0766 & 0.001 \\
2013 & 0.309 & -0.036 & 0.1065 & 3.2391 & 0.005 \\
\hline 2014 & 0.4542 & -0.0358 & 0.1164 & 4.2111 & 0.002 \\
2015 & 0.3471 & -0.037 & 0.1152 & 3.3342 & 0.004 \\
\hline 2016 & 0.4009 & -0.0371 & 0.118 & 3.7102 & 0.002 \\
2017 & 0.313 & -0.0366 & 0.1159 & 3.0156 & 0.004 \\
\hline
\end{tabular}

Moran's I: coefficient that allows the analysis of spatial autocorrelation. SD: Standard Deviation. Z: Statistics for Hypothesis Testing on the Overall Moran 's I. 
After 2015, a large cluster was centred in Inner Mongolia (44.0861N, 113.9101E) and distributed in the Northeast, North and Northwest, with the number of provinces with clusters had increased to 10. Jilin, Liaoning, Inner Mongolia, Beijing and Tianjin were the largest cluster regions of scarlet fever every year (Figure 5). The spatial-temporal scan for the period 2004-2017 showed 6 high-risk, spatial-temporal cluster regions which con- tained one most likely cluster areas (that consisted of 9 cluster provinces), 5 secondary cluster areas (that consisted of 11 cluster provinces) and 1 low-risk region. The low-risk spatial-temporal clusters were mainly in Hunan, Hubei, Jiangxi, Chongqing, Guizhou, Guangdong, Guangxi, Fujian, Anhui, Henan and Zhejiang provinces from January 2004 to December 2010 (Table 3, Figure 6).
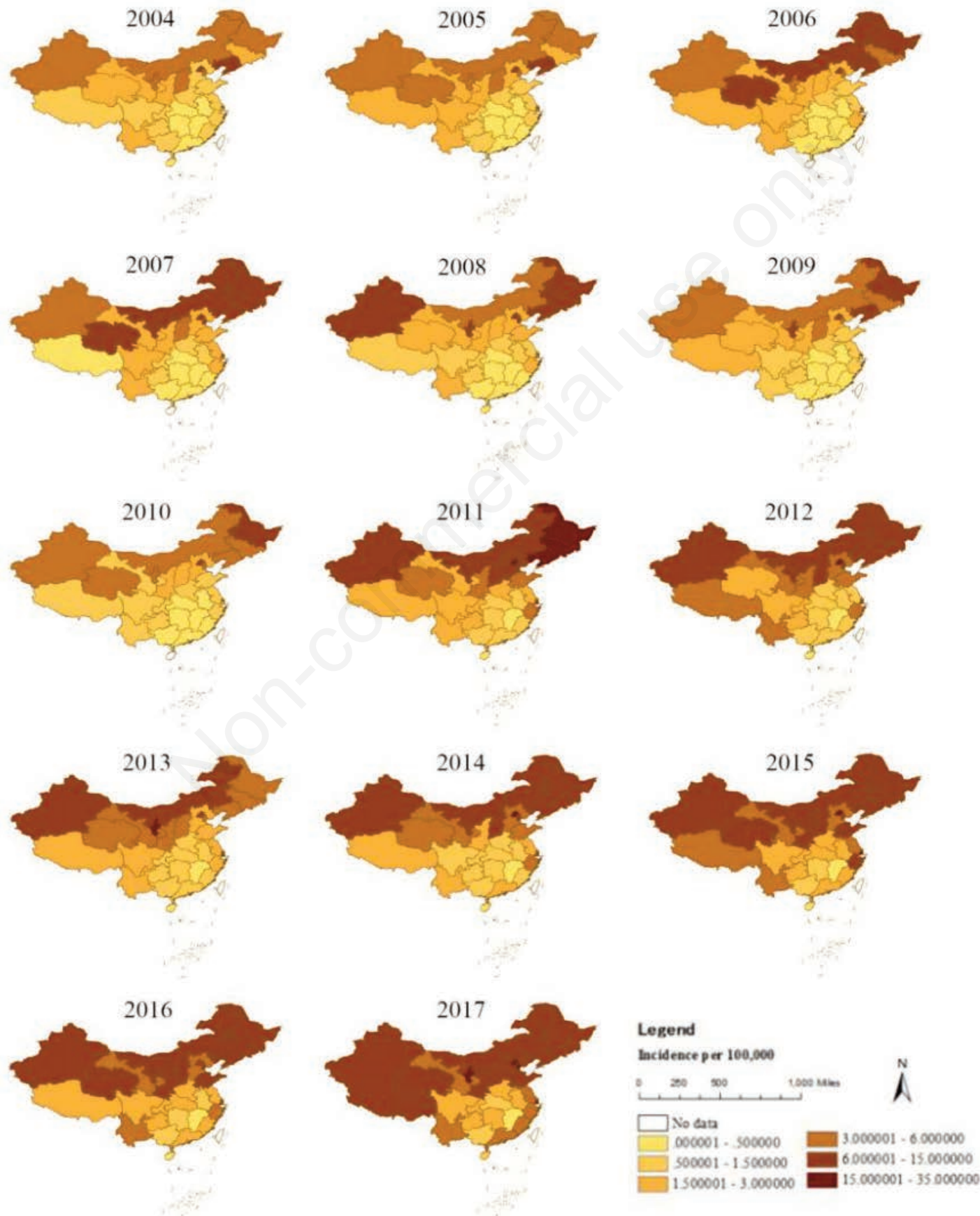

Figure 4. National thematic maps of scarlet fever incidence from 2004 to 2017. 


\section{Trend surface analysis}

The incidence of scarlet fever was taken as the dependent variable and the geographic position of each province as the independent variable to establish a 2-order trend surface model. From 2004 to 2017 , the incidence of scarlet fever showed an obvious ' $U$ ' distribution, which means low in the middle and two high sides from an east-west direction; on the other hand, the north-south distribution showed that the incidence in the northern region was significantly higher than in the southern region (Figure 7). The trend surface analysis showed that the incidence of scarlet fever was high in the northern part of China, slightly higher in the western than in the eastern part, and lower in the central part. This phenomenon indicates an evidence of high and low scarlet fever cluster areas.

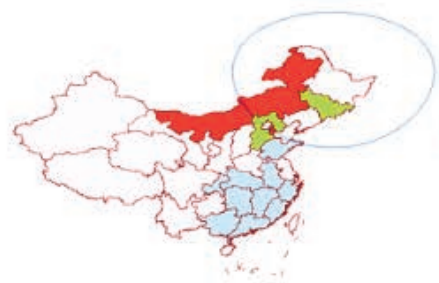

2004

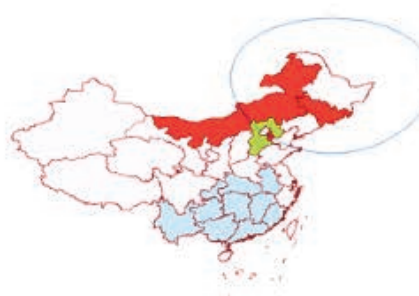

2007

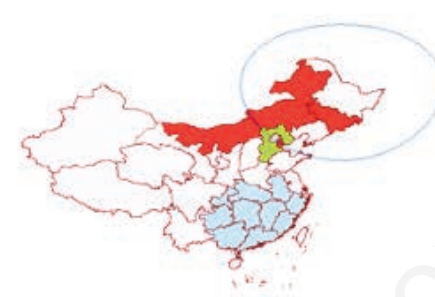

2010

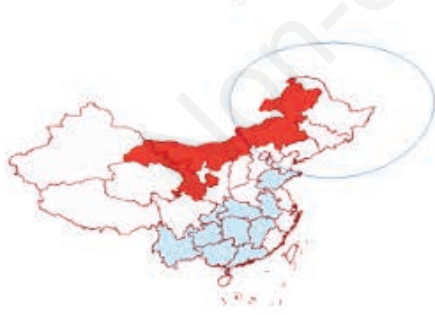

2013

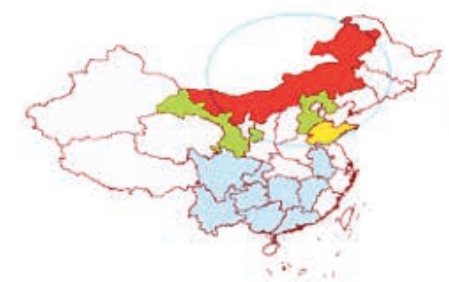

2016

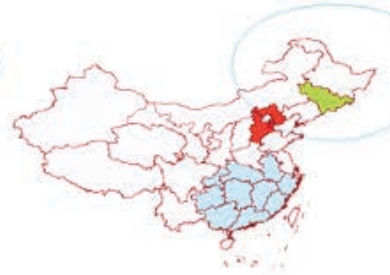

2005

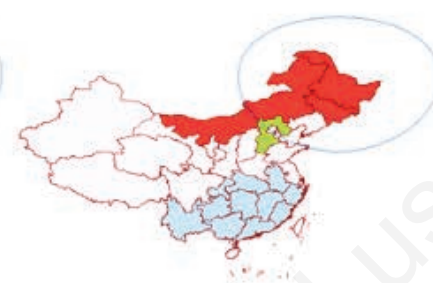

2008

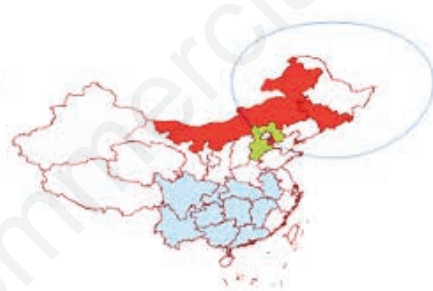

2011

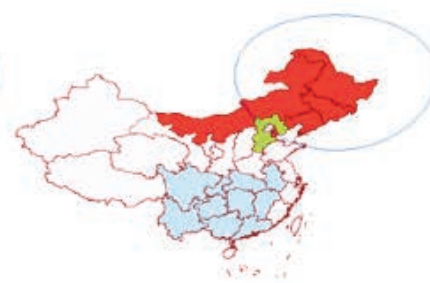

2014

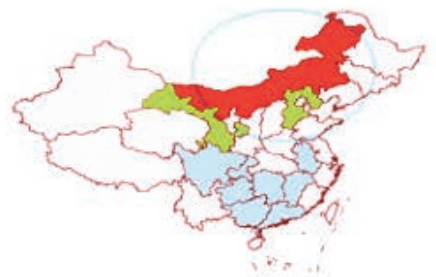

2017

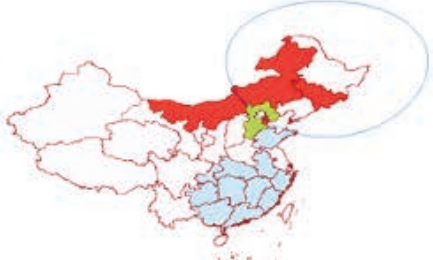

2006

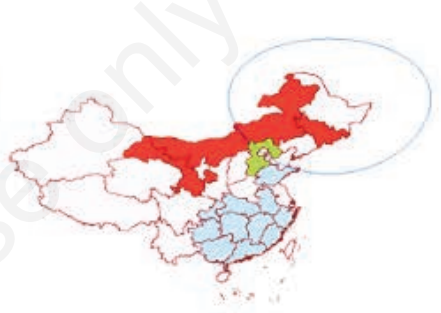

2009

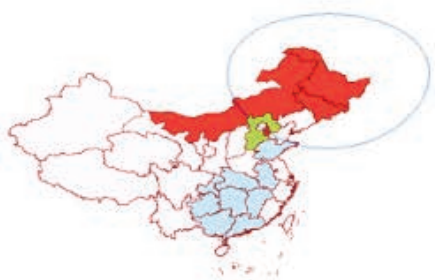

2012

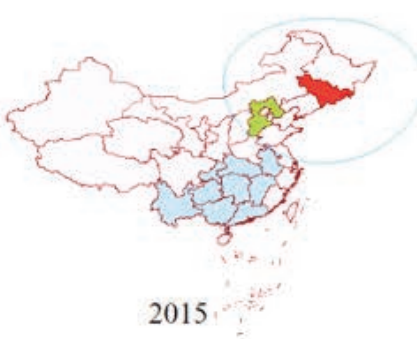

\section{Local Moran's I}

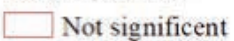

High-High Cluster

Low-Low Cluster

Low-High Cluster

High-Low Cluster

SatScan purely spatial scan

Most likely cluster

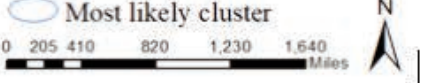

Figure 5. Visualization of Scarlet fever Spatial Clustering in China 2004-2017. 


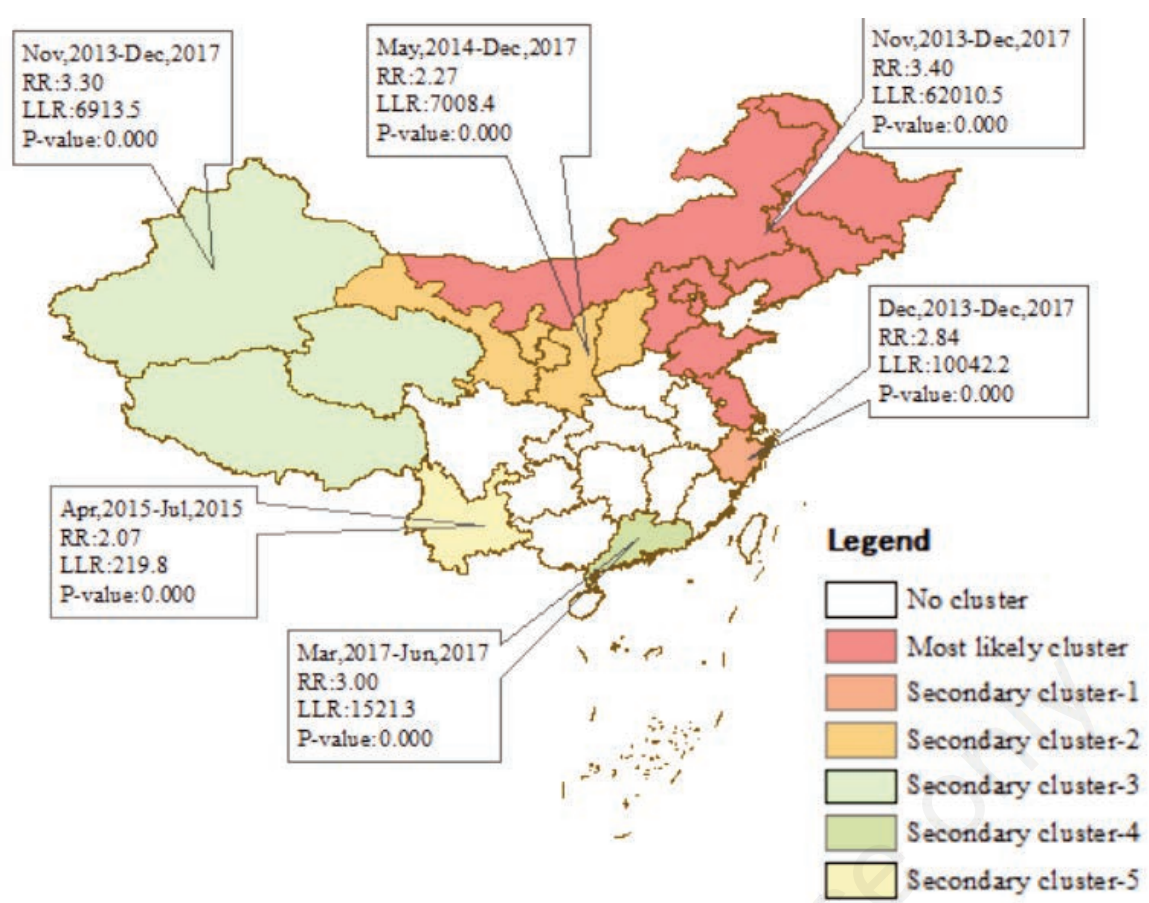

Figure 6. Distribution of spatiotemporal cluster regions of scarlet fever in China 2004-2017.

Table 2. Local spatial autocorrelation analysis of scarlet fever incidence in China, 2004-2017(LISA)

\begin{tabular}{|c|c|c|c|c|}
\hline Years & High-high cluster & Low-low cluster & High-low cluster & Low-high cluster \\
\hline 2004 & Inner Mongolia, Tianjin & $\begin{array}{l}\text { Anhui, Hubei, Chongqing, Hunan, Guangxi, } \\
\text { Guangdong, Jiangxi, Fujian, Shandong, Zhejiang }\end{array}$ & - & $\begin{array}{l}\text { Jilin, Hebei } \\
\text { Jilin }\end{array}$ \\
\hline 2005 & Hebei, Tianjin & $\begin{array}{l}\text { Anhui, Hubei, Chongqing, Guizhou, Guangxi, } \\
\text { Guangdong, Fujian, Jiangxi, Hunan, Zhejiang }\end{array}$ & & \\
\hline 2006 & Inner Mongolia, Tianjin, Jilin & $\begin{array}{l}\text { Anhui, Hubei, Chongqing, Guizhou, Guangxi, } \\
\text { Guangdong, Fujian, Jiangxi, Hunan, Shandong, Zhejiang }\end{array}$ & - & Hebei \\
\hline 2007 & Inner Mongolia, Tianjin, Jilin & $\begin{array}{l}\text { Anhui, Hubei, Chongqing, Guizhou, Guangxi, } \\
\text { Guangdong, Fujian, Jiangxi, Hunan, Yunnan }\end{array}$ & - & Hebei \\
\hline 2008 & $\begin{array}{l}\text { Inner Mongolia, Heilongjiang, } \\
\text { Jilin }\end{array}$ & $\begin{array}{l}\text { Anhui, Hubei, Chongqing, Guizhou, Guangxi, } \\
\text { Guangdong, Fujian, Jiangxi, Hunan, Yunnan, Zhejiang }\end{array}$ & - & Hebei \\
\hline 2009 & Inner Mongolia, Gansu, Jilin & $\begin{array}{l}\text { Anhui, Hubei, Chongqing, Guizhou, Guangxi, Guangdong, } \\
\text { Fujian, Jiangxi, Hunan, Shandong, Zhejiang }\end{array}$ & - & Hebei \\
\hline 2010 & Inner Mongolia, Tianjin, Jilin & $\begin{array}{l}\text { Anhui, Hubei, Chongqing, Guizhou, Guangxi, Guangdong, } \\
\text { Fujian, Jiangxi, Hunan, Zhejiang }\end{array}$ & - & Hebei \\
\hline 2011 & Inner Mongolia, Tianjin, Jilin & $\begin{array}{l}\text { Anhui, Hubei, Chongqing, Guizhou, Guangxi, Guangdong, } \\
\text { Jiangxi, Hunan, Sichuan, Yunnan }\end{array}$ & - & Hebei \\
\hline 2012 & $\begin{array}{l}\text { Inner Mongolia, Tianjin, } \\
\text { Jilin, Heilongjiang }\end{array}$ & $\begin{array}{l}\text { Anhui, Hubei, Chongqing, Guizhou, Guangxi, Guangdong, } \\
\text { Jiangxi, Hunan, Shandong }\end{array}$ & - & Hebei \\
\hline 2013 & Inner Mongolia, Gansu & $\begin{array}{l}\text { Anhui, Hubei, Chongqing, Guizhou, Guangxi, Guangdong, } \\
\text { Jiangxi, Hunan, Shandong, Yunnan }\end{array}$ & - & - \\
\hline 2014 & $\begin{array}{l}\text { Inner Mongolia, Heilongjiang, } \\
\text { Jilin, Liaoning, Tianjin }\end{array}$ & $\begin{array}{l}\text { Anhui, Hubei, Chongqing, Guizhou, Guangxi, Guangdong, } \\
\text { Jiangxi, Hunan, Sichuan, Yunnan }\end{array}$ & - & Hebei \\
\hline 2015 & Jilin & $\begin{array}{l}\text { Anhui, Hubei, Chongqing, Guizhou, Guangxi, Guangdong, } \\
\text { Jiangxi, Hunan, Yunnan }\end{array}$ & - & Hebei \\
\hline 2016 & Inner Mongolia & $\begin{array}{l}\text { Anhui, Hubei, Chongqing, Guizhou, Guangxi, Guangdong, } \\
\text { Jiangxi, Hunan, Yunnan }\end{array}$ & Shandong & Gansu, Hebei \\
\hline 2017 & Inner Mongolia & $\begin{array}{l}\text { Anhui, Hubei, Chongqing, Guizhou, Guangxi, Guangdong, } \\
\text { Jiangxi, Hunan }\end{array}$ & - & Gansu, Hebei \\
\hline
\end{tabular}


Table 3. Spatial-temporal scanning analysis of scarlet fever incidence in China, 2004-2017

\begin{tabular}{|c|c|c|c|c|c|c|c|}
\hline Cluster areas & Cluster provinces & Cluster period & Cluster centre & Scanning radius & $\mathbf{R R}$ & LLR & p-value \\
\hline Most likely cluster & $\begin{array}{l}\text { Heilongjiang, Jilin, } \\
\text { Liaoning, Inner Mongolia, } \\
\text { Beiijing, Tianjin, Hebei, } \\
\text { Shandong, Jiangsu }\end{array}$ & 2013/11-2017/12 & 43.6654N,126.1929E & $1324.46 \mathrm{~km}$ & 3.40 & 62010.5 & 0.000 \\
\hline Secondary cluster-1 & Zhejiang, Shanghai & 2013/12-2017/12 & $29.1685 \mathrm{~N}, 120.0429 \mathrm{E}$ & $249.83 \mathrm{~km}$ & 2.84 & 10042.2 & 0.000 \\
\hline Secondary cluster-2 & Ningxia, Shaanxi, Gansu, Sh & nxi2014/5-2017/12 & $37.2717 \mathrm{~N}, 106.1648 \mathrm{E}$ & $541.71 \mathrm{~km}$ & 2.270 & 7008.4 & 0.000 \\
\hline Secondary cluster-3 & Xizang, Qinghai, Xinjiang & 2013/11-2017/12 & $31.4927 \mathrm{~N}, 88.4401 \mathrm{E}$ & $1108.33 \mathrm{~km}$ & 3.30 & 6913.5 & 0.000 \\
\hline Secondary cluster- 4 & Guangdong & $2017 / 3-2017 / 6$ & $23.3518 \mathrm{~N}, 113.4229 \mathrm{E}$ & $0.00 \mathrm{~km}$ & 3.00 & 1521.3 & 0.000 \\
\hline Secondary cluster-5 & Yunnan & $2015 / 4-2015 / 7$ & $24.9758 \mathrm{~N}, 101.4877 \mathrm{E}$ & $0.00 \mathrm{~km}$ & 2.07 & 219.8 & 0.000 \\
\hline
\end{tabular}

RR: Relative Risk; LLR: Log Likelihood Ratio. p-value: Probability.

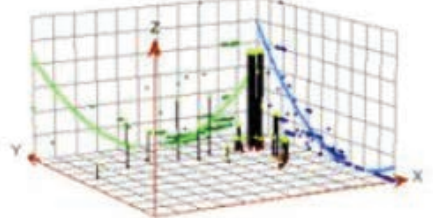

2004

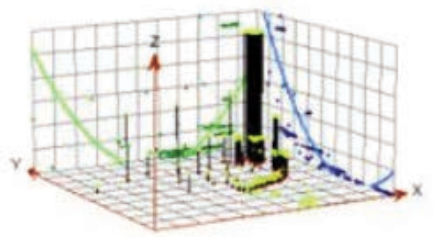

2007

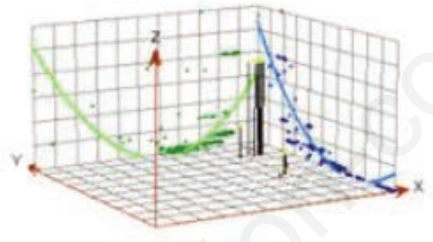

2010

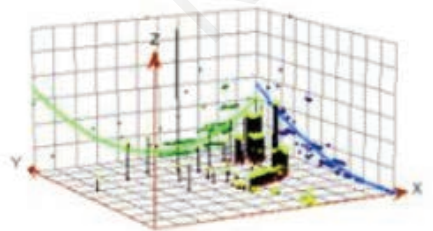

2013

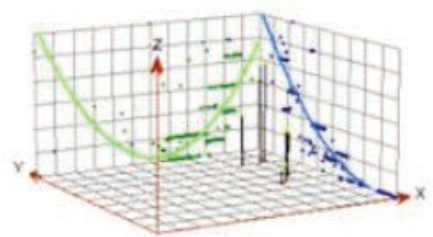

2016

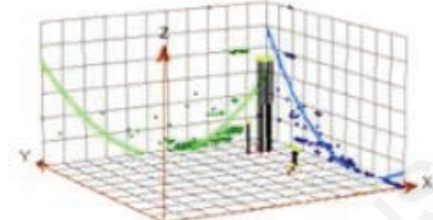

2005

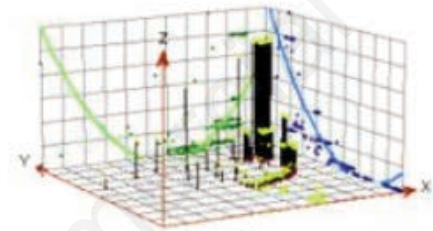

2008

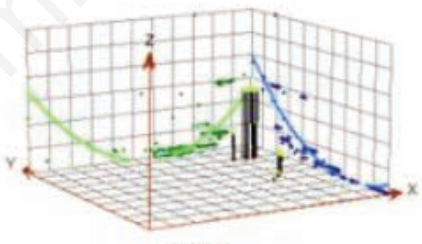

2011

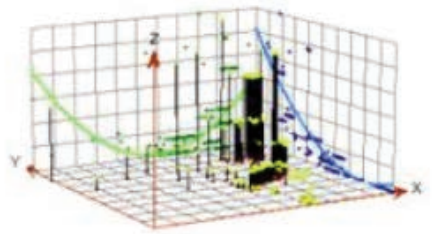

2014

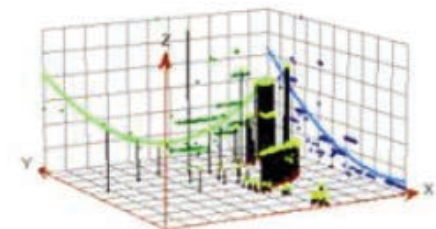

2017

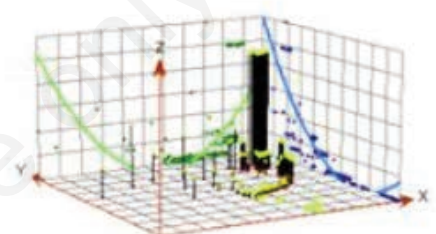

2006

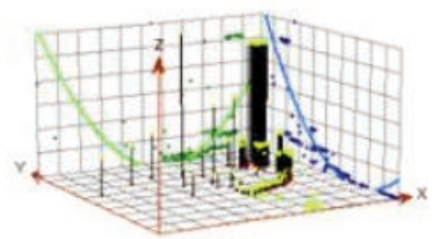

2009

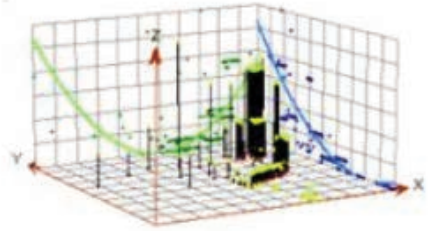

2012

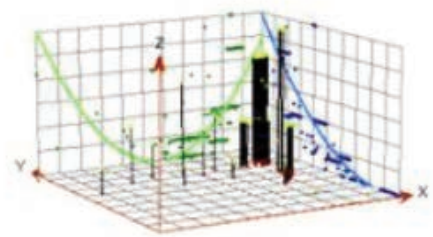

2015

Figure 7. Trend surface analysis of scarlet fever in China from 2004 to 2017 . The Z-axis represents incidence, the X-axis and Y-axis represent longitude and latitude respectively, the blue curve represents the change of the trend value in the north-south direction, and the green curve represents the change of the trend value in the east-west direction. 


\section{Discussion}

Analysis of spatial-temporal distribution characteristics of scarlet fever in China showed that its incidence has been on the rise since 2004 in mainland China, which was consistent with the trend of other parts in the country(Pan et al., 2016; Wu et al., 2017; You et al., 2018). Wong et al. (2018) also pointed out in the article that scarlet fever has reappeared in some countries in the past decade, and its incidence is on the rise. Our finding of a nationwide outbreak in 2011 has been corroborated in Hong Kong by Lau et al. (2012), in Jiangsu by Zhang (2018), in Changchun by Liu (2018) and in Beijing (Wang et al., 2019). The increasing incidence in recent years may be attributed to the accumulation of susceptible people (Wong et al., 2012). From 1995 to 2010, the incidence of scarlet fever was only sporadic without an outbreak or epidemic. Since then, the population has grown considerably, which may have added a large number of susceptible people. With the improvement of health conditions and prevention and control system of infectious disease, the increased rates of visits and diagnostic interventions might also have affected the report rate of scarlet fever to some extent (Andrey et al., 2016; Wu et al., 2017). Furthermore, Zeng et al. (1997) found that there was a typical 'Z$D$ phenomenon' in the epidemic of scarlet fever, that is, the skewness of the peak of the seasonal incidence curve was correlated to the rise and fall of the incidence in the following year, i.e. many factors that affected the first peak would continue to the next epidemic due to inertia.

The seasonal analysis showed that the incidence of scarlet fever in China has obvious seasonal variation, with a double-peak distribution, reaching the first peak in May-June and the second peak in November-December, which is similar to the results of other provincial and municipal studies in China (Li et al., 2012; Wang et al., 2016; Ning et al., 2018). Remarkably, the two peaks occurred in the first semester or the second semester of each school year of the childcare institutions and the schools. Combined with previous studies, children aged 5-15 years (appropriate ages for kindergarten or primary or middle school in China) are the main susceptible populations of scarlet fever, thus it can be inferred that this is one of the reasons for the peak. In addition, we found that the incidence of scarlet fever was lowest in February and August each year, in which childcare facilities and schools are closed. Thus, the exposure of susceptible people decreases, reducing the incidence of the disease. We recommend that surveillance of scarlet fever in school-age children be strengthened during the two peak periods.

The analysis of this study shows that there is obvious spatial clustering of scarlet fever. The high incidence areas are mainly in north-eastern China (Heilongjiang, Jilin, Liaoning), the North (Beijing, Tianjin, Hebei, Inner Mongolia, Shanxi), north-western China (Ningxia, Shaanxi, Gansu, Qinghai, Xinjiang) and some eastern coastal areas (Zhejiang, Shanghai, Shandong, Jiangsu). Meteorological conditions are possible reasons for different spatial clustering of scarlet fever among areas. Scarlet fever is an acute respiratory infectious disease, and meteorological factors play an important role in the process of transmission (Li et al., 2012). When the average temperature is low, group A Streptococcus bacterium can multiply in large numbers and spread effectively, while pathogens cannot easily spread the temperature is above $30 \square$ (Duan et al., 2016). When the temperature variation is large, children have a weak respiratory defence function due to their incomplete immune system, which results in pathophysiological reac- tions such as inflammation of the respiratory tract, which alleviates entrance of bacterial pathogens. At the same time, large temperature variations facilitate adsorption of pathogens to objects such as dust suspended in the air contributing to the risk for infection of susceptible people (Cheng et al., 2014). Dry environments, on the other hand, increases the risk of the whirling up of settled pathogens thereby providing longer exposure times, which translates into a higher risk of infection (Lowen et al., 2007; Duan et al., 2016). In China, the North is characterized by lower temperature, lower relative humidity, drier air and larger temperature variation compared to the South, all of which will promote the high incidence of scarlet fever in northern regions to a certain extent. In addition, the eastern coastal areas of China have a more developed economy, higher population density mobility, more childcare institutions and schools, and more concentrated and frequent contact among the population. All these factors provide opportunities for susceptible populations to contact pathogens closely and accelerate the speed of transmission of the pathogen.

Currently, tertiary prevention is the main measure to prevent and control scarlet fever in China due to no effective vaccine against scarlet fever. Scarlet fever has been on the rise across the country in recent years, it is necessary for local health and medical institutions to strengthen the surveillance and management of the source of infection, carry out health education, and popularize the prevention and treatment of scarlet fever for the sake of treatment of this disease. In particular, the principle of 'early detection, report, diagnosis, isolation, and treatment' should be strictly followed in the beginning of the two peak periods. Measures like indoor ventilation, keeping the indoor air clean, can help to protect the vulnerable population in the high-incidence cluster regions.

The limitation of this study is that we lack access to information, such as drug resistance, health status, socioeconomic factors, etc. In further research, we will combine these factors to comprehensively explore the key factors of scarlet fever.

\section{Conclusions}

In summary, our research systematically explored the temporal and spatial variation of scarlet fever in mainland China from 2004 to 2017. The incidence of scarlet fever is generally on the rise and has significant seasonality and spatial regionality. The high-risk area is mainly distributed in parts of northeast China, north China, northwest and east coast, which will help to control the epidemic of scarlet fever more effectively. The health department should strengthen the monitoring and prevention of scarlet fever in the country, especially in high-risk areas and peak periods of scarlet fever.

\section{References}

Andrey DO, Posfay-Barbe KM, 2016. Re-emergence of scarlet fever: old players return? Expert Rev Anti Infect Ther 14:6879.

Cheng J, Xu Z, Zhu R, Wang X, Jin L, Song J, Su H, 2014. Impact of diurnal temperature range on human health: a systematic review. Int J Biometeorol 58:2011-24. doi:10.1007/s00484014-0797-5.

Duan Y, Huang XL, Wang YJ, Zhang JQ, Zhang Q, Dang YW, 
Wang J, 2016. Impact of meteorological changes on the incidence of scarlet fever in Hefei city, China. Int J Biometeorol 60:1543-50.

Jiang QW, Zhao F, 2011. [Application of spatial autocorrelation method in epidemiology] [Article in Chinese]. Chin J Epidemiol 32:539-46.

Kirby RS, Delmelle E, Eberth JM, 2017. Advances in spatial epidemiology and geographic information systems. Ann Epidemiol 27:1-9. doi:10.1016/j.annepidem.2016.12.001.

Kong DC, Chen J, Wang Y, Zhu YY, Zheng YX, Pan H, Wu HY, 2017. [Epidemiologic characteristics of scarlet fever in Shanghai, 2005-2015]. [Article in Chinese]. Dis Surveillance 32:394-8.

Lau EH, Nishiura H, Cowling BJ, Ip DK, Wu JT, 2012. Scarlet fever outbreak, Hong Kong, 2011. Emerg Infect Dis 18:17002. doi: 10.3201/eid1810.120062.

Li LL, Jiang XH, Sui X, Ni DX, Jin LM, Feng ZJ, 2012. [Epidemiologic characteristics of scarlet fever in China, 20052011]. [Article in Chinese]. Chin J Public Health 28:826-7.

Liu YY, 2018. [Epidemiological Characteristics and Trend Prediction of Scarlet Fever from 2007 to 2016 in Changchun]. [Article in Chinese]. Jilin University. Available from:https:/ /kns.cnki.net/KCMS/detail/detail.aspx?dbcode $=$ CMFD\&dbna $\mathrm{me}=\mathrm{CMFD} 201901 \&$ filename $=1018213642 . n h \& \mathrm{v}=\mathrm{Mjk} 4 \mathrm{Nzgz}$ UFZGMjZGckc1SGRmSXJaRWJQSVI4ZVgxTHV4WVM3 RGgxVDNxVHJXTTFGckNVUjdxZlkrWnRGeW5uVTc $=$.

Liu ZY, Bi ZQ, 2014. [A review on the advancement of aetiology and epidemiology of group A Streptococcus]. [Article in Chinese]. Chin J Epidemiol 35:752-754.

Lowen AC, Mubareka S, Steel J, Palese P, 2007. Influenza virus transmission is dependent on relative humidity and temperature. PLo S Pathog 3:1470-6. Available from: https://journals. plos.org/plospathogens/article?id=10.1371/journal.ppat.0030151

Moran PAP, 1950. Notes on continuous stochastic phenomena. Biometrika. 37:17-23. doi:http://dx.doi.org/10.1093/ biomet/37.1-2.17.

National Bureau of Statistics of China. Sixth census data in China. Available from: http://www.stats.gov.cn/.

Ning SQ, Chen S, Cao L, Zhou TC, Wang WH, Wang S, Zhang Y, 2018. [Epidemiological characteristics and trend of scarlet fever in Shaanxi Province from 2010 to 2016]. [Article in Chinese]. Chin J Dis Con Prev 22:585-9.

Pan HH, Liu XQ, Yang M, Yuan H, 2016. [Epidemiological characteristics of scarlet fever in Jiangxi Province from 2004 to 2014] [Article in Chinese]. Mod Prev Med 43:577-9.

Tami A, Grillet ME, Grobusch MP, 2016. Applying geographical information systems (GIS) to arboviral disease surveillance and control: a powerful tool. Travel Med Infect Dis 14:9-10. doi:10.1016/j.tmaid.2016.01.002.

Tang JH, 2011. [Application of Geographic Information System technology in disease prevention and control]. [Article in Chinese]. Anhui J Prev Med 17:113-6.

Tsai P J, Lin M L, Chu C M, Perng CH, 2009. Spatial autocorrelation analysis of health care hotspots in Taiwan in 2006. BMC
Public Health 9:464. doi: 10.1186/1471-2458-9-464.

Wang L, Zhang L, Wang T, Yang SX, Kou ZQ, Fang M, Bi ZQ, Bi ZW, 2016. [Incidence trend and epidemiological characteristics of scarlet fever in Zibo City from 1956 to 2014]. [Article in Chinese]. Chin J Dis Con Prev 20:349-52.

Wang Y, Wei ZS, Lai CY, Wu F, Gao JJ, Zhang GQ, Li YL, Zhang WJ, 2019. [Epidemiological characteristics of scarlet fever in Haidian district of Beijing from 2011 to 2017]. [Article in Chinese]. Mod Prev Med 46:2895-8.

Wong SSY, Yuen KY, 2012. Streptococcus pyogenes and re-emergence of scarlet fever as a public health problem. Emerg Microbes Infect 1:1-10. doi: https://doi.org/10.1038/ emi.2012.9.

Wong SSY, Yuen KY, 2018. The Comeback of Scarlet Fever. EBioMedicine 28:7-8. doi:10.1016/j.ebiom.2018.01.030.

Wu SS, Ma CN, Peng XM, Zhang DT, Wang QY, Yang P, 2017. [Characteristics on the onset features of scarlet fever in Beijing, 2006-2015]. [Article in Chinese]. Chin J Epidemiol 38:514-7. doi:10.3760/cma.j.issn.0254-6450.2017.04.020

Xue FZ, Wang JZ, Zhang JW, Zhang YJ, 2004. [Order-selecting methods for trend surface model of spatial distribution of disease]. [Article in Chinese]. Journal of Shandong University (Health Sciences) 2:125-30.

Yang SG, Dong HJ, Li FR, Xie SY, Cao HC, Xia SC, Yu Z, Li LJ, 2007. Report and analysis of a scarlet fever outbreak among adults through food-borne transmission in China. J Infect 55:419-24.

You YH, Song YY, Yan XM, Wang HB, Zhang MH, Tao XX, Li LL, Zhang YX, Jiang XH, Zhang BH, Zhou H, Xiao D, Jin LM, Feng ZJ, Luo FJ, Zhang JZ, 2013. Molecular epidemiological characteristics of streptococcus pyogenes strains involved in an outbreak of scarlet fever in China, 2011. Biomed Environ Sci 26:877-85.

You Y, Davies MR, Protani M, McIntyre L, Walker MJ, Zhang J, 2018. Scarlet fever epidemic in China caused by streptococcus pyogenes serotype M12: epidemiologic and molecular analysis. EBioMedicine 28:128-35. doi:10.1016/j.ebiom.2 018.01. 010.

Zeng G, Ding YP, Cheng YH, 1997. [Demonstration On Z-D phenomenon in the occurrence of infectious diseases]. [Article in Chinese]. Chin J Epidemiol 5:270-4. Available from: http://www.chinacdc.cn/en/publication/cje/.

Zhang MY, Lv Y, Liu TC, Yi SH, Zha WT, 2019. [Spatial-temporal analysis and short-term prediction of the incidence of dysentery in China]. [Article in Chinese]. Chinese Journal of Disease Control and Prevention 23:904-10.

Zhang Q, 2018. [The research on epidemic characteristics of scarlet fever and impact of meteorological factors on scarlet fever in Jiangsu Province]. [Article in Chinese]. Nanjing Medical University. Available from: https://kns.cnki.net/KCMS/detail/ detail.asp $x$ dbcode $=$ CMFD \& dbname $=$ CMFD201802 \& filename $=1018185429 . n h \& v=M T U x O D M 2 R n J L d 0 c 5 W E 9 w c E$ ViUE1SOGVYMUx1eFITN0RoMVQzcVRyV00xRnJDVVI3 cWZZK1p0RnlubVY3ek5WRjI=. 